\title{
Правовые особенности транспортировки арктических углеводородов (Российское, Канадское, международное право)
}

Буник И.В.

Арктические минеральные ресурсы, по определению, данному в юридической литературе' это минеральные ресурсы, залегаюшие в пределах наземных, подземных, водных, подводных пространств Арктики, в т.ч. в недрах суши, морского дна, а также во льдах. По некоторым естественнонаучным данным, арктические минеральные ресурсы являются самым значительным, пока не истошенным резервом для будуших поколений приарктических государств, прежде всего России и Канады - стран с самым протяженным арктическим побережьем. Правовой режим арктических минеральных ресурсов зависит прежде всего от международно-правового статуса того пространства Арктики, где эти ресурсы залегают. Например, режим минеральных ресурсов архипелага Шпицберген определен в основном Договором о Шпицбергене 1920 г.; минеральных ресурсов полуострова Аляски - российско-американским Договорои об успупке Аляски 1867 г. и законодательством США, действующим после этой даты; ресурсов острова Гренландия - национальным законодательством Дании как государства, осушествляюшего суверенитет над Гренландией. По действующему законодательству Канады (Закон 1925 г.; королевский указ 1926 г.; Закон 1970 г. и др.), ее суверенитет распространяется на все земли и острова в пределах сектора, образованного меридианами 60 и $141^{\circ}$ 3. д. и северным побережьем Канады. При этом не уточняется, означает ли здесь термин «земли», кроме материковых земель, также ледяные глыбы и дно под Северным Ледовитым океаном в пределах указанного канадского сектора. В этих пределах Канада осуществляет, на основе Закона и международного права, контроль над иностранной деятельностью в целях предотвращения загрязнения

\footnotetext{
- Буник Нван Владимирович - юрист Совета по изучению прокзводительных сил при IІрезидиуме РАН.

'Правовой режим минеральных ресурсов / Под ред. В.Ж. Аренса, А.Н. Вылегжанина. Кемерово-Томск, 2002. С. 23-24.
} 
арктических вод. В понятие «арктические воды» канадским законом отнесены и «природные богатства подводных зон». Некоторыми правительственными заявлениями Канады весь район в пределах указанного канадского полярного сектора квалифицирован как «национальное пространство» на основе исторических прав; особых климатических и географических обстоятельств, в т.ч. фактора прилегания (contiguity); международно-правовых обязательств Канады защитить от загрязнения свой арктический сектор. По законодательству России (царские указы 1616-1620 гг.; распоряжения 1833 и 1869 гг; указ Сената 1821 г; инструкция 1893 г; нота МИД России 1916 г.; постановление Президиума ЦИК СССР 1926 г. и др.) предусмотрен ряд исключительных прав России в некоторых районах Арктики. Так, упомянутой нотой МИД России 1916 г. подтверждалась принадлежность России островов, которые «составляют продолжение к северу континентального пространства Сибири». Последним из перечисленных правовых актов объявлены территорией страны «все как открытые, так и могущие быть открытыми в дальнейшем земли и острова, не составляющие к моменту опубликования настоящего постановления признанной правительством Союза ССР территории каких-либо иностранных государств, расположенных в Северном Ледовитом океане к северу от побережья Союза ССР до Северного полюса в пределах между меридианом 32 градуса 04 минуты 35 секунд восточной долготы... и меридианом 168 градусов 49 минут 30 секунд западной долготы». В международно-правовой теории предложено под термином «земля) понимать также «ледяные глыбы и омываюшие их воды» в пределах обозначенного полярного сектора ${ }^{2}$. Однако российскими законами, в отличие от канадских, не предусмотрен контроль над $n p u$ родными богатствами всего арктического сектора, обозначенного постановлением 1926 г. Мнения в правовой доктрине о правах России на все природные ресурсы в пределах указанного арктического сектора расходятся. Кроме Канады и России, имеғоших самое протяженное арктическое побережье, ни одной из других стран, побережье которых выходит к Северному Ледовитому океану (США, Норвегия или Дания), не установлен законом полярный сектор в Арктике. В доктрине этих стран пространственные пределы суверенитета и суверенных прав на арктические минеральные ресурсы определены так, как если

2 См., например: Лахтин В.Л. Права на северные полярные пространства. М., 1928; Коровин Е.А. СССР и полярные земли // Советское право. № 3. 1926. С. 46. 
бы Арктика была не средоточением ледяных глыб, а типичным районом оживленного морского судоходства. Согласно Декларации о зашите окружающей среды 1991 г., тексту Стратегии зашиты окружающей среды 1991 г. и Декларации об учреждении Арктического совета 1996 г. к арктическим государствам отнесены, кроме пяти стран, побережье которых выходит к Северному Ледовитому океану, также Финляндия, Исландия, Швеция. Эти же восемь стран отнесены к арктическим согласно Икалуитской декларации 1998 г. министров' государств - членов Арктического совета ${ }^{3}$.

Морская транспортировка добытых в Арктике полезных ископаемых может осуществляться судами или по трубопроводу (проложенному по дну Северного Ледовитого океана или в его льдах), в т.ч. трансграничному, то есть пересекающему по крайней мере одну государственную границу.

Правовое регулирование транспортировки углеводородов в Арктике имеет свою специфику вследствие ряда обстоятельств. Как уже отмечалось, в Арктике осуществляют свою юрисдикцию два арктических государства, имеющих самое протяженное побережье в Северном Ледовитом океане - Российская Федерация и Канада. Конвенция ООН по морскому праву 1982 г. специально не устанавливает правовой режим Арктики, имея в виду то, что вопросы использования арктических пространств достаточно предметно и эффективно регулируются исторически на национальном уровне. Применимость к Арктике норм Конвенции ООН по морскому праву 1982 г. имеет сушественную специфику. В настоящее время целевая юрисдикция арктических государств осуществляется прежде всего для защиты хрупкой арктической окружающей среды, сохранения биоразнообразия, экосистемного управления и т.д. В то же время, как неоднократно отмечалось многими отечественными правоведами, сохраняется инициированная Канадой в 1925 г. система арктических секторов (арктический сектор - это треугольник, образованный побережьем арктического государства и меридианами, сходящимися в точке Северного географического полюса и проходящими через западную и восточную оконечности такого побережья). По смыслу законодательства двух арктических стран - Канады и России - их секторы остаются зоной реализации исторически сложившихся оборонных, особых экономических, природоресурсных и природоохранных интересов конкретного арктического государства 4 .

\footnotetext{
Т Там же. С. 25.
} 
Анализ законодательной практики сопредельных к арктическому региону стран (Канады, России, США, Дании, Норвегии), касающейся установления правового режима Арктики и регулирования всех видов деятельности в ее пределах, позволяет сделать вывод о том, что общий правовой режим региона, обособленного в географическом и политико-административном отношении, формировался под воздействием ряда факторов природного, исторического, экономического, демографического и военно-политического порядка. Особенности геополитического положения арктических государств обусловили их заинтересованность в осушествлении надзора над всеми видами деятельности, проводимой в прилегающих арктических водах. Северный морской путь Российской Федерации, шхерный морской путь «Индрелея» Норвегии, Северо-западный проход Канады объединяет то, что все они являются историческими национальными морскими путями указанных государств (и не являются международными проливами), так как находятся в стороне от путей международного судоходства или ведут к их историческим заливам и морям. Арктические государства стремятся усилить роль национального законодательства в общем правовом режиме прилегаюших к их побережью районов Арктики. Данное стремление легко объяснить: ведь в случае аварий, связанных с утечкой углеводородов, больше всего пострадают именно арктические государства. Первый проект Правил Международной морской организации (ИМО) для судов, находящихся в арктических водах, был предложен в 2002 г. ${ }^{5}$ Неизвестно, сколько времени пройдет, прежде чем будет утвержден окончательный вариант, в какие сроки Правила вступят в силу, и вступят ли вообще. Вместе с тем канадское национальное законодательство вот уже более 30 лет зффективно регулирует деятельность в Арктике, снижая экологические риски.

Идеи интернационализации Арктики вообще и арктических судоходных путей (Севморпути и Северо-западного прохода) в частности не получили поддержки в актах национального и международного права. В настоящее время международное сотрудничество государств по вопросам зашиты окружаюшей среды Арктики и ее устойчивого развития ограничено рамками деятельности Арктического Совета,

${ }^{4}$ Вылегжанин А.Н., Гуреев С.А., Иванов Г.Г. Международнее норское право. Отв. ред. Гуреев С.А. М., 2003. С. 213. См. также: Малеев Ю.Н. Глава 6 в: Межодународное прсво/ Отв. ред. Колосов Ю.М., Кривчикова Э.С. М., 1999. С. 125.

:Draft MSCMEPC Circular On Guidelines For Ships Operating In Arctic lce-Covered Waters // DE 45/27/Add. 21 July 2002. 
созданного в качестве «форума». Выбор такой организационной структуры соответствует современной практике неформального межгосударственного сотрудничества (например, ОБСЕ) и оказывает существенное влияние на то, как Совет выполняет свои функции.

В Арктическом Совете и его вспомогательных органах возможно обсуждение важных вопросов с учетом того, что решение принимается на основе консенсуса всеми восемью арктическими странами. Поэтому решення устраивают всех участников и выполняются всеми ${ }^{6}$. Реализация любых инициатив возможна только после одобрения Министрами арктических стран. Старшие должностные лица по Арктике (англ. senior arctic officials), руководяшие работой Совета, лишь подготавливают предложения для передачи их на утверждение Министров. Таким образом, Совет представляет из себя скорее форум для обмена мнениями, а не орган, регламентирующий деятельность в Арктике; Арктический Совет не ограничивает правотворческие и правоприменительные функиии арктических государств, в том числе и по установлению правового режима транспортировки углеводородов ${ }^{7}$. Государства по отдельности или коллективно могут действовать независимо от Совета.

Вышеизложенное позволяет сделать вывод: в международном праве признается, что вопросы использования арктических пространств, вопросы транспортировки арктических углеводородов регулируются прежде всего на национальном уровне; международное право санкционирует более строгие национальные меры арктических государств по защите окружающей среды Арктики.

Вместе с тем в силу ряда причин прокладка и эксплуатация трубопроводов в Арктике должны осуществляться с учетом не только норм национального, но и международного права.

Во-первых, экспорт углеводородов предполагает прокладку трансграничных трубопроводов; при этом делимитация в Арктике не получила окончательного правового урегулирования ${ }^{8}$, однако возможно заключение соответствующего межгосударственного соглашения о едином правовом режиме трансграничного трубопровода.

\footnotetext{
${ }^{6}$ Declaration on the Establishment of the Arctic Council, 35 ILM 1387 (1996), a также Arctic Council Rules of Procedure, Rule 7.

${ }^{7}$ Подробнее см.: Bloom E. Establishment of the Arctic Council // 93 AJIL 712 (1999).

${ }^{8}$ Вылегжанин А.Н., Гуреев С.А., Иванов Г.Г. Международное.иорское право. М., 2003. C. 224-226.
} 
Во-вторых, существует ряд международных конвенций, регулирующих морскую нефтегазовую деятельность вообще и в Арктике в частности (например, Конвенция ООН по морскому праву 1982 г., Международная конвенция по предотвращению загрязнения с судов 1973 г. и Протокол 1978 г. (МАРПОЛ 73/78), Конвенция по предотврашению загрязнения моря сбросами отходов и других материалов 1972 г.).

В-третьих, в рамках упомянутого Арктического Совета осуществляется международное сотрудничество в Арктике (главным образом по вопросам зашиты окружаюшей среды и устойчивого развития).

В связи с рассмотрением вопросов, касающихся правового режима арктических трубопроводов, интерес представляют Правила морской нефтегазовой деятельности в Aрктике 1997 2. (Arctic Offshore Oil and Gas Guidelines), принятые в соответствии со Стратегией защиты окружающей среды Арктики (АЕПС) (далее - Правила). Эти Правила применимы и к морской транспортировке углеводородов по трубопроводу из месторождений, находящихся в Арктике.

Министры Канады, Дании, Исландии, Финляндии, России, Швеции, Норвегии и США приняли упомянутые Правила по итогам Четвертой министерской встречи по защите арктической окружающей среды в июне 1997 года. Принятие Правил предполагает, что дальнейшее совершенствование регулирования может быть оформлено национальным законодательством. На национальном уровне могут быть установлены более строгие требования, что особо подчеркивается в Правилах. Правила адресованы не только национальным органам власти, но и нефтегазовым компаниям.

Правила перечисляют и раскрывают содержание Принципов морской нефтегазовой деятельности в Арктике: принцип осторожного подхода (Principle of the Precautionary Approach); принцип «загрязнитель платит» (Polluter Pays Principle); принцип устойчивого развития (Sustainable Development).

Правила предписывают установку, эксплуатацию и поддержание трубопроводов способами, которые не создают неоправданных затруднений для иных видов использования морского дна. До принятия стандартов проектирования арктических трубопроводов Правила обязывают учитывать в процессе проектирования информацию о таянии льдов, иные особенности ледовой обстановки; систему катодной зашиты трубопроводов, возможность контроля качества и профилактического обслуживания. 
Операторы арктических трубопроводов должны иметь План действий при разливе нефти в случае повреждения трубопровода. В Плане должны быть указаны лица, привлекаемые к действиям в чрезвычайных ситуациях (представители государственных и частных структур, организаций здравоохранения, ученые, пострадавшие коренные жители, доверенные лица нефтегазовой компании и иные лица, потенциально могущие пострадать от аварии или оказать содействие в ликвидации последствий). План должен содержать подробные сведения, имеющие значение в случае действий при разливе нефти (напр., глубина воды; карты; предписания по транспортировке, хранению и захоронению разлившейся нефти; перечень необходимого для ликвидации последствий оборудования и др.).

Правила (Раздел 8) регулируют процесс прекращения эксплуатации и демонтажа трубопровода. Проект демонтажа трубопровода должен быть предусмотрен на стадии проектировки и пересмотрен непо средственно при прекращении использования трубопровода. В случае прекращения транспортировки углеводородов трубопровод либо удаляется, либо остается на морском дне in situ после промывания содержимого.

В соответствии со ст. 60 Конвенции ООН по морскому праву 1982 г. Международная морская организация ИМО 19 октября 1989 года приняла Правила и стандарты по удалению морских установок и сооружений, расположенных на континентальном шельфе и в исключительной экономической зоне (IMO Guidelines and standards for the removal of offshore installations and structures on the Continental shelf and in the Exclusive economic zone) $)^{9}$. Правила ИМО (п. 3.13) запрещают после 1 января 1998 года размешение на континентальном шельфе или в исключительной экономической зоне любых установок и сооружений, если их проект и конструкция не предусматривают возможности полного удаления после прекращения использования или оставления. Согласно Правилам ИМО, прибрежное государство обеспечивает, что: неиспользуемые установки и сооружения над уровнем моря должным образом содержатся, при этом назначается ответственное лицо; водяной столб над остатками частично удаленных сооружений не может быть менее 55 метров (это актуально для арктических морей, глубина которых редко превышает 200 метров); информация о всех сооруже-

\footnotetext{
${ }^{9}$ Resolution A.672(16).
} 
ниях отражается в соответствующих навигационных картах; возможна ответственность за причинение ущерба.

Государства - участники Арктического Совета (Дания, Финляндия, Исландия, Норвегия, Швеция) подписали и ратифицировали региональное соглашение - Конвенцию по защите морской среды северовосточной Атлантики 1992 г. Конвенция вступила в силу 25 марта 1998 года. Помимо перечисленных стран, Конвенция ратифицирована также Бельгией, Францией, Германией, Ирландией, Нидерландами, Португалией, Испанией, Соединенным Королевством Великобритании и Северной Ирландии. В случае реализации проекта транспортировки углеводородов по трубопроводу в любую из упомянутых стран следует учитывать предписания Статьи 5 Приложения III к Конвенции «О предотвращении и устранении загрязнения от источников на море»:

во-первых, не допускается дампинг не используемых более морских установок и трубопроводов; не используемая более морская установка не должна полностью или частично оставаться в море без разрешения компетентного органа Государства - участника Конвенции;

во-вторых, такое разрешение не выдается в случае, если не используемые более установка или трубопровод содержат вешества, способные навредить здоровью человека, живым биологическим ресурсам, морским экосистемам, отдыху или иному законному виду морепользования;

в-третьих, Государство-участник, намеревающееся выдать разрешение на дампинг установок и трубопроводов, размещенных после 1 января 1998 года, должно посредством созданной в соответствии с Конвенцией Комиссии уведомить других участников о причинах, в целях проведения возможных консультаций;

в-четвертых, Государства-участники должны вести и предоставлять Комиссии записи об установках и трубопроводах, в отношении которых был осушествлен дампинг, о времени, месте и способе дампинга, а также об установках и трубопроводах, оставленных in situ.

Инвесторам следует учитывать нормы Конвенции по защите морской среды северо-восточной Атлантики 1992 г. в процессе нефтегазовой деятельности. Например, в соответствии с Конвенцией на оператора трубопровода в Великобритании был наложен значительный штраф за утечку 450 тонн нефти ${ }^{10}$.

${ }^{10}$ OSPAR Commission. Annual Report on Discharges, Waste Handling and Air Emissions from Offshore Oil and Gas Installations, in 2002 // Offshore Industry Series, 2004. 
В связи с тем, что некоторые арктические страны являются членами Европейского сообшества, отметим обязательную для них Директиву об оченке воздействия на окружаюицю среду 1985 г. (Environmental Impact Assessment Directive), с изменениями от 1997 г." . Директива предусматривает обязательную предварительную оценку проектов, связанных с прокладкой трубопроводов для транспортировки углеводородов (диаметром более 800 мм и длиной более 40 км); при принятии решений учитывается общественное мнение.

Арктический район транспортировки углеводородов является районом конкурирующих видов морской деятельности: нефтегазовых разработок, судоходства, рыболовства, зверобойного промысла и т.д. Поэтому к арктическому району применима методология комплексного управления прибрежными зонами (КУПЗ) ${ }^{12}$. КУПЗ представляет собой в первую очередь экономико-правовой инструмент гармонизации многочисленных противоречивых интересов прибрежных природопользователей. Методология КУПЗ разработана как ответ на обострение проблем их социально-экономического развития, приводящих к потере способности устойчивого развития этих одних из наиболее используемых районов в мире. КУПЗ определяется как процесс разработки и выполнения скоординированной стратегии, направленной на распределение и разделение природных, социо-культурных и иных ресурсов с целью сохранения и устойчивого многостороннего использования прибрежной зоны и ее ресурсов. КУПЗ исходит из взаимосвязанности видов прибрежного природопользования и окружающеей среды, на которую они потенциально воздействуют. Такое управление нацелено на преодоление фрагментарности, присущей отраслевому подходу. КУПЗ имеет многоцелевую ориентацию, оно анализирует участие сторон в развитии побережий, конфликтное использование ресурсов, взаимосвязь природных процессов и человеческой деятельности, способствует связям и межотраслевой гармонизации прибрежной/морской деятельности. КУПЗ должно проводиться на государственном уровне и включать формирование институциональных рамок, необходимых для обеспечения интеграции планов развития и управления в прибрежных зонах с природоохранными целями (в том числе и в социальном аспекте) и для участия заинтересованных

\footnotetext{
"Council Directive 97/11/EC of 3 March 1997.

'2 См. об этом подробнее: «Комплексное управление прибрежными зонами. Правовой глоссарий» / Под ред. А.Н. Вылегжанина. Рига, 2005.
} 
сторон в разработке этих планов. Процесс планирования и управления должен носить комплексный характер и учитывать все секторные мероприятия, оказывающие воздействие на прибрежную зону и ее ресурсы и связанные с социально-экономическими и природоохранными вопросами. Это предусматривает разработку, обновление и усиление средств нормативного регулирования; совершенствование схем районирования, направленное на разделение прибрежной зоны на участки, предназначенные для определенного использования и видов деятельности; развитие управленческих программ, направленных на развитие конкретных ресурсов или конкретных участков побережья, восстановление поврежденных ресурсов, решение проблем береговой линия; создание программ поощрения новых видов экономической деятельности в прибрежной зоне и др. Конференция ООН по окружающей среде и развитию в 1992 г. рекомендовала странам, имеюшим выход к морю, разрабатывать и осуществлять программы КУПЗ в соответствии со своими условиями (гл. 17, «морская», Повестки дня на $X X I$ век). Всемирные конференции по океанам, побережьям и островам 2001 и 2003 гг. (Париж), Всемирная встреча на высшем уровне по устойчивому развитию (Йоханнесбург, 2002 г.) подтвердили, что методология КУПЗ является эффективным механизмом выполнения гл. 17 Повестки дня на XXI век. За последние десять лет интерес к КУПЗ приобрел в мире глобальный характер. В настоящее время уже свыше ста стран реализуют ориентированные на КУПЗ программы. Согласно подготовленному Советом Европы Модельному закону об устойчивом управлении прибрежными зонами, КУПЗ означает устойчивое развитие и использование прибрежных зон, которое принимает в расчет уровень экономического и общественного развития, связанного с морем, сохранение и защиту ландшафта, хрупкого биологического и экологического баланса прибрежной зоны для настояшего и будущих поколений. Введение КУПЗ подразумевает, в частности, необходимость институциональных и юридических мер обеспечения участия всех заинтересованных сторон в принятии решений о развитии района и координации политики и действий национального, регионального и местного уровня. КУПЗ обосновывает необходимость подхода к решению возможных проблем не по мере их возникновения, а с позиции заблаговременного всестороннего исследования, учитывающего взаимодействие между всеми компонентами, составляющими окружсаюиуюо среду ${ }^{13}$.

${ }^{13}$ Там же. C. 59-61. 
Применение КУПЗ в Арктике позволит эффективнее защищать окружаюшую среду и по трассам Северного морского пути.

$* * *$

Северный морской путь - основная транспортная коммуникация в российском арктическом секторе, соединяющая Дальний Восток и западные районы страны и играющая ключевую роль в инфраструктуре экономического комплекса Крайнего Севера России и в освоении природных ресурсов Северного Ледовитого океана ${ }^{14}$. Увеличение объема национальных и международных грузоперевозок по Северному морскому пути отвечает экономическим интересам нашей страны. Дальнейшее развитие судоходства и создание условий эффективного государственного управления арктическим сектором требуют развития и совершенствования нормативно-правовой базы, относяшейся к этому региону. Этот процесс, несомненно, должен происходить в соответствии с нормами международного права и с учетом зарубежного правового опыта.

Ряд обстоятельств затрудняет применение в полном объеме и без каких-либо ограничений норм Конвенции ООН по морскому праву 1982 г. к правовому режиму арктических морей России. Совершенствование правового регулирования судоходства по Севморпути - задача прежде всего национального законодательства Российской Федерации. Макроэкономические перспективы использования этого судоходного пути придают упомянутой задаче особую актуальность и значение, предполагаюшие разработку специального федерального закона, посвященного исключительно этому вопросу.

Международно-правовым основанием для разработки такого закона являются не только права арктических государств, исторически сложившиеся и давно осуществляемые, не только суверенитет России над внутренними морскими водами, но и права, предусмотренные в ст. 234 Конвенции по морскому праву $1982 r^{15}$, которую Россия ратифицировала в 1997 г. $^{16}$. Согласно положениям ст. 234 этой Конвенции, при-

i О правовом режиме морских природных ресурсов см. Вылегжанин А.Н. Морские природные ресурсы (иеждународно-правовой режии). М., 2001.

${ }^{15}$ Конвенция Организации Объединенных Наций по морскому праву (Монтего-Бей, 10 декабря 1982 г.) // С3 РФ от 1 декабря 1997 г., № 48, ст. 5493.

16 Федеральный закон оr 26 февраля 1997 г. № 30-Ф3 «О ратификации Конвенции Организации Объединенных Наций по морскому праву и Соглашения об осушествлении части XI Конвенции Организации Объединенных Наций по морскому праву» // С3 РФ от 3 марта 1997 г,, № 9, ст. 1013. 
брежные государства имеют право принимать и обеспечивать соблюдение недискриминационных законов и правил по предотвращению, сокращению и сохранению под контролем загрязнения морской среды с судов в покрытых льдами районах в пределах исключительной экономической зоны, где особо суровые климатические условия и наличие льдов, покрывающих такие районы в течение большей части года, создают препятствия либо повышенную опасность для судоходства, а загрязнение морской среды могло бы нанести тяжелый вред экологическому равновесию. В развитие этой статьи в России должны быть приняты соответствующие нормативно-правовые акты.

Разработка проекта Федерального закона «О Северном морском пути» была предусмотрена еще Планом законотворческой работы Правительства РФ на 2003 г. Совету по изучению производительных сил при Президиуме РАН было поручено в связи с этим разработать проект концепции и предварительный (рабочий) вариант законопроекта ${ }^{17}$.

Основной целью проекта является подтверждение и уточнение статуса и правового режима Северного морского пути, а также связанных с эксплуатацией Северного морского пути мер по предотвращению, сокращению и сохранению под контролем загрязнения морской среды с судов в покрытых льдами районах в связи с повышенной опасностью для судоходства и угрозой экологическому равновесию от загрязнения морской среды. Законопроект составлен с учетом международного опыта разработки правовых норм и стандартов в данной области, а также национального опыта других арктических государств - CША, Норвегии и особенно Канады, раньше России проявившей заинтересованность в определении статуса Северо-западного прохода. Этот опьт представляет большой интерес и для нашей страны.

Действие закона предполагается распространить на невоенные суда, допушенные на трассы Северного морского пути, плавающие под Государственным флагом Российской Федерации, и суда, плавающие под флагами иностранных государств, заходящие в порты, открытые для международного судоходства (в том числе суда, осуществляющие транспортировку углеводородов), а также на российские и иностранные военные корабли.

С точки зрения перспектив уточнения законодательного режима Севморпути интересен опыт решения схожего вопроса Канадой.

17 Подробнее см.: Гуреев С.А., Буник И.В. «К кониепиии проекта Федерального закона «О Севернон .иорскои пути» // МЖМП № 1/2005/57. 
Правовые проблемы использования Северо-западного прохода Канады обсуждаются уже давно, особенно в контексте оформления Канадой Законом 1925 г. своих прав на канадский арктический сектор.

В качестве примера внутригосударственного законодательства по вопросам правового режима арктических пространств остановимся на канадском Законе о предотвращении загрязнения арктических вод 1970 г. (англ. Arctic Waters Pollution Prevention Act 1970) ${ }^{18}$ с изменениями и дополнениями (последнее от 30 апреля 2002 года, см. Revised Statutes of Canada 2002, c. 10 s. 177). Канадским Законом 1970 г. определены специальные зоны для государственного контроля - "Shipping safety control zones" и установлены широкие права по контролю за загрязнением в районах на расстоянии 100 миль от любой точки канадского берега к северу от $60^{\circ}$ северной широты (т.е. от любого канадского острова в ее арктическом секторе), тем самым в пределах всего сектора Канады в Арктике правительство получило законодательную возможность осушествлять эффективный государственный контроль за соблюдением иностранцами национального законодательства Канады, прежде всего в области зашиты окружаюшей среды. Отметим, что вслед за принятием Закона 1970 г. последовали ожесточенные дебаты противников и сторонников распространения Канадой юрисдикции на ее арктический сектор. Резкие выпады последовали и от некоторых иностранных властей, в особенности со стороны США ${ }^{19}$.

Что касается непосредственно статуса Северо-западного прохода, то исследователи отмечают возможность возникновения серьезных правовых коллизий в случае перспективы дальнейшего таяния льдов ${ }^{20}$. Официальная позиция канадского правительства относит Северозападный проход к внутренним историческим водам. Это означает, что Канада заявляет о суверенитете в отношении этих вод и регулирует любую деятельность в их пределах. Так, в своем выступлении перед Палатой общин 10 сентября 1985 года министр иностранных дел

189 INT. LEGAL MATERIALS 543 (1970). Комментарий к Закону см.: Wilkes, International Due Process and Control of Pollution - The Canadian Arctic Waters Example. 2 J. MAR. L. \& COMM. 499(1971).

${ }^{19}$ CM., Hanp., Department of State Release. April 15, 1970. 64 AM. J. INT'L. L. 928 (1970); Terrance Wills. U.S. won't accept Canadian claims over Arctic waters // The Globe and Mail, 10 April 1970.

${ }^{20}$ Huebert R. Climate change and Canadian sovereigntv in the Northwest Passage// Volume 2 № 4. Winter 2001 . 
Дж. Кларк заявил: «Суверенитет Канады в Арктике неделимый. Он охватывает землю, море и лед. Он распространяется до внешних берегов арктических островов. Эти острова едины и не разделяются водами между ними. Большую часть года они соединены льдом. С незапамятных времен канадский народ инуитов использовал и занимал лед так же, как использовал и занимал сушу» ${ }^{21}$. С 1985 г. Министерство иностранных дел Канады не делало последующих официальных заявлений. В июне 2000 года Министерство иностранных дел выступило с новым заявлением о внешней политике по вопросам Арктики, где вторым из четырех направлений обозначено "провозглашение и обеспечение сохранения канадского суверенитета на Севере» ${ }^{22}$. Однако в заявлении не конкретизируется, каким именно образом Канада намеревается это осуществить. Упоминается лишь, во-первых, спад интереса общественности к вопросам суверенитета и, во-вторых, влияние глобализации на осуществление государственного суверенитета посредством развития юридически обязательных многосторонних соглашений, неофициальных договоренностей и учреждений.

Вопрос о судьбе Северо-западного прохода в связи с актуальной в наши дни перспективой таяния льдов рассматривался в докладе, представленном 19 марта 2001 года на конференции в Уайтхорсе, посвяшенной проблемам суверенитета Канады в Арктике. Хотя доклад правительственного чиновника не может быть расценен как официальное заявление, имеются все основания полагать, что был обозначен обший подход Министерства иностранных дел. В докладе было отмечено, что «канадский суверенитет не зависит от наличия или отсутствия льдов, а основан на праве исторических вод, возникшем после передачи Великобританией Канаде в 1880 г. арктического архипелага. Эти воды использовались инуитами - канадскими подданными - с незапамятных времен. Канада осуществляла в отношении этих вод безусловный и постоянный суверенитет» ${ }^{23}$. При этом подчеркивалось: Канада не придерживалась концепции отождествления ледяных массивов и суши; таким образом, даже таяние льдов не повлияет на канадский сувере-

${ }^{21}$ External Affairs Canada, Statements and Speeches // "Policy on Canadian Sovereignty", September 10, 1985.

22 Department of Foreign Affairs and International Trade. The Northern Dimension of Canada's Foreign Policy. (n.d.), p. 2 // Цит. nо: Huebert R. Climate change and Canadian sovereignty in the Northwest Passage // Volume 2 № 4. Winter 2001.

":M. Gaillard, Legal Affairs Bureau, Department of Foreign Affairs and International Trade // Canada's Sovereignty in Arctic Waters. March 19, 2001. Whitehorse, Yukon. 
нитет, основанный на законном статусе исторических вод, а не факте наличия льда.

В связи с ограниченностью канадских возможностей осуществлять наблюдение в Арктике современные исследователи прогнозируют действия США, направленные на участие американцев в контроле за деятельностью в данном регионе. США могут заявить о своих интересах на основе популярных в последнее время идей борьбы с терроризмом: раз Канада не способна гарантировать безопасность США от возможного проникновения террористов через северные территории, то этим придется заняться США 24 .

Кстати, в связи с проблемой «исключительного контроля» интересны недавние высказывания некоторых канадских военных, касающиеся развития национальных средств наблюдения в Арктике. «Природные ресурсы становятся все более доступны, важно поддерживать наш суверенитет», - цитирует канадская газета. Военные планируют ввести в эксплуатацию систему наблюдения, основанную на спутниковом мониторинге арктических проливов, полетах автоматически управляемого самолета и высокочастотных радарах, установленных в точках западного и восточного захода на трассу Северо-западного прохода ${ }^{25}$.

То, что действия Канады не противоречат нормам международного права, было основательно показано американскими специалистами по международному праву ${ }^{26}$.

Правительство Канады не раз подчеркивало, что факт распространения юрисдикции основан не на одних лишь национальных интереcax, а на действиях в интересах всего человечества при отсутствии эффективных норм международного права. Так, канадский премьерминистр, специалист по конституционному праву П.Э. Трюдо в свое время сделал следующее заявление: «...в условиях, когда не существует права или правовое регулирование явно не эффективно и нет общей международно-правовой нормы касательно арктических морей, мы утверждаем, что кто-то обязан сохранить этот район в интересах всего человечества, - не дожидаясь дальнейшего развития международного права» ${ }^{27}$. Территориальная юрисдикция как установленная законода-

${ }^{24}$ Huebert R. Northern interests and Canadian foreign policy. Calgary University Press, 2004.

${ }^{25}$ Weber B. Commander: Arctic defence needs airlift capacity // Canoe Cnews, 8 April 2005. ${ }^{26}$ См., например: John C. Klotz. Are Ocean Polluters Subject to Universal JurisdictionCanada Breaks the Ice // The International Lawyer, Vol. 6. № 4, October 1972 P. 706.

${ }^{27}$ Press conference of Prime Minister Trudeau. April 8, $1970 / / 9$ INT. LEGAL MATERIALS $601(1970)$. 
тельством совокупность правомочий соответствующих государственных органов разрешать правовые споры и решать дела о правонарушениях, то есть оценивать действия субъекта права с точки зрения их правомерности и применять юридические санкции к правонарушителям, представляет собой судебный, законодательный и административный аспекты общей правовой компетенции государства ${ }^{28}$.

В соответствии с упомянутым канадским Законом о предотвращении загрязнения арктических вод 1970 г. принят ряд важных подзаконных нормативно-правовых актов, определяющих порядок транспортировки углеводородов в Арктике. Так, например, Правила по предотвращению загрязнения с судов в Арктике (англ. - Arctic Shipping Pollution Prevention Regulations ${ }^{29}$ ) устанавливают технические требования к перевозящим углеводороды судам. Правила по предотвращению загрязнения арктических вод (англ. - Arctic Waters Pollution Prevention Regulations ${ }^{30}$ ) предусматривают гражданско-правовую ответственность и условия освобождения от нее за сброс отходов с судов, а также за загрязнение в процессе иной деятельности, связанной с добычей углеводородов (транспортировки по трубопроводу, хранения, разработки месторождения). Верхний предел такой ответственности - 40 млн. долл.

В соответствии с Законом о судоходстве (англ. - Canada Shipping $\mathrm{Act}^{3 !}$ ) приняты Правила по предотвращению загрязнения нефтью (англ. - Oil Pollution Prevention Regulations ${ }^{32}$ ). Эти правила применяются в отношении всех морских пространств, находящихся под канадской юрисдикцией.

Надзор за соблюдением канадского законодательства о транспортировке углеводородов в Арктике осушествляют инспекторы по предотвращению загрязнения (англ. - pollution prevention officers). Инспекторы вправе осматривать любые суда или сооружения, связанные с добычей и транспортировкой нефтепродуктов.

$* * *$

Арктический регион интересен для энергетических компаний своими богатыми природными ресурсами. Транснациональные компании

${ }^{28}$ Пиголкин А.С. Юрисдикция // Юридический знциклопедический словарь. 2-е изд. / Под ред. А.Я. Сухарева М., 1987. С. 526.

${ }^{29}$ Consolidated Regulations Of Canada, 1978.

30 Ibid.

"Revised Statutes of Canada, 1985; с изм. и доп.

:Consolidated Regulations Of Canada, 1978. Посл. изм. от 21 ноября 2002 г. (SOR/2002-425). 
заинтересованы в разработке месторождений и последующей морской транспортировке полезных ископаемых на судах или по трубопроводу.

Арктика в то же время остается районом, особо уязвимым в экологическом отношении. Разработка и транспортировка углеводородов будет происходить при повышенных экологических рисках. Поэтому специфика региона предполагает осуществление такой деятельности с учетом исторически сложившихся исключительных прав арктических государств, что означает строгое соответствие национальному законодательству указанных государств, а не только более общим (и, как правило, не столь жестким) нормам международного права. 